\title{
Biografía y novela biográfica. Autobiografía del general Franco de Manuel Vázquez Montalbán como novela biográfica de carácter dialógico, político y crítico*
}

\section{Biography and biographical novel. Manuel Vázquez Montalbán's Autobiografía del general Franco as a biographical novel of a dialogical, political and critical nature}

\author{
JOSÉ R. VALLES CALATRAVA \\ Universidad de Almería, España. \\ Correo electrónico: jrvalles@ual.es
}

Este artículo aborda, en primer lugar, las similitudes y diferencias entre biografía y novela biográfica, un subgénero poco estudiado. En segundo término, analiza Autobiografía del general Franco (1992) de Manuel Vázquez Montalbán, una obra que, empleando la forma dialógica, la inclusión de sociolectos y la intertextualidad documental, constituye una reciente y excelente novela biográfica española de carácter crítico, dialógico y político.

Palabras clave: novela española contemporánea, Vázquez Montalbán, biografía, novela biográfica, dialogismo

This article examines firstly the similarities and differences between biography and biographical novel, a rather understudied minor genre. Secondly, it analyzes Manuel Váquez Montalban's Autobiografía del general Franco (1992), a work that, through the dialogic form, the inclusion of sociolects and the documentary intertextuality, appears as a recent and excellent Spanish biographical novel of a critical, dialogical and political nature.

Key words: Spanish contemporary novel, Vázquez Montalbán, biography, biographical novel, dialogism

Este artículo fue elaborado en el marco del Proyecto I+D (España): FFI2017-86040-P, "Cartocronografría de los relatos de viaje españoles contemporáneos (siglos XIX y XX)”. 


\section{INTRODUCCIÓN}

En octubre de 2017 se cumplieron 25 años de la aparición de la obra de Manuel Vázquez Montalbán (Barcelona, 1939-Bangkok, 2003) Autobiografía del general Franco $(1992)^{1}$, cuya leyenda de cubierta, en la primera edición de Planeta ("una novela que recupera del olvido toda la crueldad de una época”), seguida más abajo de la ilustración de Franco vestido de falangista y rodeado por la bandera española que portaba (reproducción de un conocido retrato de Ignacio Zuloaga), proclamaban patente y doblemente el tema personal o, mejor, biográfico del relato (la vida del general Franco) junto al muy explícito carácter político, memorialístico y justiciero, de tal narración (la historia española, y particularmente de la dictadura [1939-1975], a través de la revisión crítica de la figura del citado dictador ${ }^{2}$ ).

Periodista y ensayista, poeta y novelista, intelectual y político, gastrónomo y futbolero, el prolífico autor barcelonés, conocido internacionalmente y por el gran público sobre todo por su ciclo de novela negra protagonizado por el detective Pepe Carvalho, fusiona aquí elementos procedentes de las distintas memorias personales -incluidas las de Franco y el autor- con fuentes documentales testimoniales, históricas o periodísticas sobre Franco, el franquismo y la evolución de la realidad nacional española del siglo XX (la literatura como una doble ars historica y ars mnemonica) en un relato temáticamente biográfico y político, estilísticamente dialógico y coral e intencionalmente desmitificador y crítico: de ahí el título de este trabajo.

Vázquez Montalbán se sirve de un alter ego, el escritor antifranquista y represaliado Marcial Pombo, al que se encarga una biografía divulgativa y positiva de la vida de Franco y que termina redactándola en un diálogo permanente, tanto verbal como discursivo, entre el pseudo-yo de Franco, relator con su propia voz de su propia historia, y el yo del escritor ficticio/narrador/personaje, que cuenta alternativamente la suya propia e interpela y cuestiona permanentemente con numerosos apoyos documentales la objetividad y veracidad de las palabras del anterior.

Entre un Introito, donde Pombo cuenta el encargo editorial y recapitula sobre su vida sentimental y política, y un Epílogo, en que narra la entrega del libro y reflexiona sobre su situación personal y la situación española en la época de la transición postfranquista a la democracia, se encierra todo el panorama de la vida de Franco en un relato enclavado metadiegéticamente (Genette 1972: 238; Bal 1987: 140-142; Pimentel 2005: 148) dentro del anterior, organizado en varios capítulos ${ }^{3}$, ficcionalizado pero lleno de referencias

\footnotetext{
1 Traducida, al menos, al portugués, francés, italiano y holandés; premio internacional Ennio Flaiano en 1994. Un estudio previo, básico y más breve sobre las relaciones transtextuales de la novela puede verse en Valles (1999).

2 "Un monumento antifranquista" es el título de la crítica que Haro Tecglen hizo en Babelia, El País (31-10-1992) cuando vio la luz la novela.

3 Correspondientes a sucesivos periodos de la vida de Franco: Infancia y confesiones, La llamada de África, Las afinidades nunca son electivas, La Cruzada de liberación, Lo que piensa el Caudillo Franco no lo sabe, Rey sin corona y ¿Con quién están?
} 
a hechos históricos y seres reales y discursivamente mostrado en forma narrativa pero con una permanente contraposición dialógica -en el sentido más originario de Bajtín (1986) - no sólo entre la voz y visión de Franco y Pombo, sino asimismo entre el discurso autoritario y monológico franquista y el contrapuesto y políticamente alternativo, plural y prodemocrático.

\section{Autobiografía del general Franco, ¿̨NOVEla histórica, de dictador, biográfica?}

Sin entrar aquí en la espinosa cuestión de los subgéneros literarios, particularmente los que se definen de modo esencial por razones temáticas (novela del oeste, bélica, policiaca/criminal, de ciencia-ficción, histórica, de espionaje, etc.) como la mayor parte de los novelescos ${ }^{4}$, resulta evidente que Autobiografía del general Franco mantiene evidentes conexiones con la novela histórica en la medida en que supone un ejercicio narrativo de reconstrucción ficcional de tipo realista de un pasado histórico.

Amado Alonso (1984), tras repasar la evolución de la novela histórica desde los precedentes prerrománticos hasta sus últimas manifestaciones del siglo XX pasando por la novela histórica romántica y realista, concluye que esta modalidad narrativa no es tanto la que narra o describe hechos ocurridos o existentes sino aquella que específicamente se propone reconstruir un modo de vida pasado y ofrecerlo como pretérito y que, a consecuencia de este programa estético, el escritor adopta una actitud informativa, de orden intelectual, que irremediablemente desaloja o estorba la acción puramente creadora y poética. Y Gyorgy Lukacs (1966), en el aún mejor estudio sobre el género pese a su antigüedad, destaca como rasgos caracterizadores del mismo el sentido histórico, la revitalización profunda y realista del pasado, el carácter popular, la aplicación al presente, el anacronismo necesario y el uso de personajes típicos.

Sin duda, como he dicho ya e ilustra el fragmento del relato antes reproducido, esta narración de Vázquez Montalbán guarda bastantes similitudes con la novela histórica, si bien no me parece ni exclusiva ni primordialmente adscribible a tal subgénero por su centramiento temático esencial en la narración de una trayectoria vital y política.

Por tales razones, más conexiones aprecio con la novela de dictador, una variedad narrativa caracterizada por su esencia política y por la asunción del personaje del dictador de uno de sus roles actanciales fundamentales, y no tanto por otra serie de otros muy diversos rasgos formales, lingüísticos o estructurales. Se trata de una modalidad característica de la literatura contemporánea latinoamericana de la pasada centuria conformada por un numeroso

\footnotetext{
4 Al criterio temático principal podrían añadirse otros cuatro que originan otra serie de denominaciones: el de edición (novela de masas, folletinesca, dime novel, pulp...); el del grado de ficcionalidad o mimetismo (novela realista, fantástica, objetivista, idealista, no ficción o faction...); el del componente estilístico o discursivo (novela experimental, ensimismada, novela lírica/dramática/épica, polifónica, nouveau roman...); y la perspectiva puramente epocal (novela clásica, medieval, contemporánea, dieciochesca...) o estético-cultural (novela barroca, vanguardista, romántica, postmoderna...) (Valles, 2008: 70-76).
} 
grupo de relatos ${ }^{5}$, entre los que destacan Tirano Banderas (1926) de Valle-Inclán, El Señor Presidente (1946) de Miguel A. Asturias, Muertes de perro (1959) de Francisco Ayala, Yo, el Supremo (1974) de Roa Bastos, El recurso del método (1974) de Carpentier, El otoño del patriarca (1975) de García Márquez y La fiesta del chivo (2000) de Vargas Llosa.

De todas estas obras, sin duda la que más parecido guarda con la de Vázquez Montalbán es Yo, el Supremo. Ambas novelas localizan la acción en una época y país concreto y se refieren a unos hechos y a un modelo de personaje reales (Paraguay, siglo XIX, Gaspar de Francia/España, siglo XX, Francisco Franco); las dos emplean la voz directa del dictador para relatar su visión de la realidad y de sí mismos; ambas pretenden recrear directa pero críticamente un discurso político dictatorial. Incluso parece haber una idea global compartida sobre la dictadura — si bien con diferencias políticas—, que es el que expuso Augusto Roa Bastos en un periódico español: "Es muy difícil que un dictador acepte su régimen como un acto de culpabilidad, porque ellos creen que se trata de un acto de bien nacional, de orden y de tranquilidad para la población. Por supuesto, estos argumentos son completamente falsos, porque el poder dictatorial es siempre destructivo y negativo. Es un mal que, como todos, nunca puede hacer el bien" (Sábato y Roa Bastos 1998: 27).

En absoluto me parece erróneo incluir este relato del escritor barcelonés en la nómina de las novelas de dictador. Entiendo, no obstante, que tanto el indicador de la mención paratextual del título (Autobiografía del general $\underline{\text { Franco }^{\sigma}}$ ), con referencia directa a la forma narrativa y al personaje central -con un modelo real-, como el carácter eminente y explícitamente político de la estructura contraautoritaria de la obra, que, frente a la palabra y visión del dictador, integra y recodifica en el relato, transdiscursiviza, los sociolectos ${ }^{7}$ de los distintos lenguajes sociales y políticos antifranquistas y prodemocráticos de la España del fin de la dictadura y la etapa de la transición, lo diferencian y distancian de las grandes obras de ese subgénero narrativo.

De hecho, la alusión titular en un juego literario falaz a la autobiografía, el centramiento temático en la narración de una vida completa -aunque en su proyección política nacional española-, refiriéndose además a un modelo real de personaje y siguiendo un orden cronológico -con comienzo ab ovo-, y el uso de un complejo aparato crítico y documental para pretender dar más veracidad que verosimilitud al relato [alternativo] sitúan claramente la obra en el campo biográfico. Y, sin embargo, la cuádruple referencia

\footnotetext{
$5 \quad$ Sin ánimo de exhaustividad y sí de apertura y correlación, cabe indicar que, desde Amalia, la figura del dictador aparece en otras muchas novelas, sea como personaje antirrevolucionario (novela mexicana y cubana de la revolución) o ser hiperbólicamente caricaturizado (Zalamea, Aguilera Malta, Lafourcade...), sea construyendo el relato desde una perspectiva simbólica y alegórica (Scorza, Mateos, Bedoya, Alegría...) o como una tesis política adoctrinadora (Blanco Fombona, Vargas Vila...).

6 Los subrayados son siempre míos.

7 Uso aquí el término en el sentido de transdiscursivización de los discursos de los distintos grupos sociales —y políticos - en el texto narrativo, según lo plantea en general la sociocrítica de Cros (1998) y particularmente Zima (1980; 1982).
} 
al estatuto novelesco de la misma en los paratextos editoriales (tres identificaciones como novela en contracubierta y una en cubierta), la existencia de narrador, personajes, acontecimientos, espacios y tiempos absolutamente imaginarios, ficcionales, en la historia principal y diégesis primaria, el carácter metadiegético o enmarcado de la doble narración secundaria autobiográfica y biográfica a cargo de los respectivos personajes Franco y Pombo, tan pretendidamente veraz en su contenido [particularmente la biográfica] como falaz en cuanto a la veracidad de los sujetos de tal enunciación secundaria, la libertad narrativa máxima de que hace gala Vázquez Montalbán con el ya aludido carácter político, dialógico y crítico del relato y, por último, su consiguiente clara ubicación en el ámbito de la ficción -si bien cerca de la factualidad biográfica- me inclinan a situar architextualmente esta obra como un excelente ejemplo de novela biográfica, un subgénero novelesco difícilmente localizable en la mayoría de los catálogos de los mismos y que pretendo caracterizar a continuación.

\section{BIOGRAFÍA ${ }^{8} \mathrm{Y}$ NOVELA BIOGRÁFICA}

\section{I. El SUjeto biográfico}

En sus estudios sobre la autobiografía ${ }^{9}$, Philippe Lejeune la caracteriza, entre otras vinculaciones, por sus similitudes y diferencias con respecto a la biografía. Ambas son textos referenciales, por pretender informar sobre la realidad externa y poseer su ilusión de veracidad, al igual pues que los textos históricos y científicos. No obstante, las dos se diferencian fundamentalmente porque, entre las cuatro instancias del autor, narrador, personaje y modelo real, la relación esencial es de supuesta identidad en la autobiografía -confusión del autor y del modelo- y, en cambio, en la biografía lo es de semejanza similitud de personaje y modelo-: en su reducción a dos fórmulas textuales, mientras en la autobiografía el Narrador es al Personaje lo que el Autor es al Modelo, en la biografía el Autor es o no es el Narrador, y el Personaje se asemeja al Modelo. Además y con respecto a la persona narrativa -yo/tú/él-, paralela pero inversamente a la autobiografía, siempre en

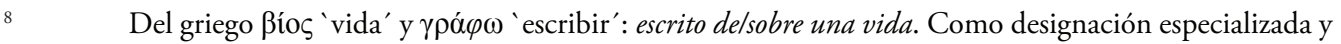
en su doble forma culta e inglesa (Biographia/Biography), el término no aparece hasta bien entrado el siglo XVII, en concreto con la edición en 1683 por el dramaturgo y crítico inglés John Dryden de las Vidas de Plutarco, donde define asimismo el género como "historia de vidas de hombres particulares".

$9 \quad$ Si bien fue Gusdorf (1991: 9-17) el que abrió en 1956 los análisis sobre la autobiografía como modalidad literaria y, a diferencia de la línea crítica que marcaba el nacimiento moderno del género con las Confesiones (h. 1770) de Rousseau, consideró que existía desde los más antiguos tiempos, es Lejeune - precisamente partidario de la otra opción — quien, aunque matizando progresivamente su visión de la autobiografía en sucesivos libros y ampliando su campo de análisis hasta llegar a analizar los diarios íntimos, aportó con su idea del pacto autobiográfico, entre otras características identificativas, una sistematización del estudio de la misma como género específico (Lejeune 1975, 1980).
} 
autodiégesis (Hawthorn 1997: 92), pueden existir la biografía en primera persona como un relato de testimonio -homodiegético-, la biografía dirigida al propio modelo en segunda persona y la biografía clásica y común -heterodiegética- en tercera (Lejeune 1975: 13-46).

Así pues, en coherencia y consecuencia con las tesis de Lejeune, el texto biográfico se caracterizaría porque: a) la relación entre personaje textual y persona extratextual-modelo-es fundamentalmente de semejanza [ $\sim$; b) la relación entre sujeto de la enunciación y sujeto del enunciado -biógrafo/biografiado, narrador/protagonista- es de alteridad [‡]; c) el narrador puede mostrarse bien como un relator heterodiegético bien como un relator homodiegético, participante o no en la historia que cuenta pero siempre ajeno al personaje ${ }^{10}$.

En este último sentido, escribe Romera Castillo que "en la escritura biográfica, el sujeto de la historia recibe la mirada del otro" (1996: 79) y, citando la obra de Ricoeur Soi-même comme un autre, Dosse incide en esa dialéctica del yo y del otro como elementos coactuantes en la biografía:

Si tomamos en serio la bella demostración de Ricoeur según la cual el sí mismo (Ipse) se construye no en una repetición del mismo (Idem) sino en la relación con el otro, la escritura biográfica está muy cerca de ese movimiento hacia el otro y de la alteración del yo hacia la construcción de un sí mismo convertido en otro (Ricoeur 1990; Dosse 2007: 14).

Y es que, ciertamente, entre ambos, biógrafo y biografiado, se impone una relación especial, oscilante y de necesario y variado ajuste, entre omnisciencia y ajenidad, entre cercanía y lejanía, entre distancia y empatía; como indica Daniel Madelénat todo relato biográfico se desarrolla siempre entre dos actitudes opuestas: "Ocultación, sumisión, referencia, camaleónicas metamorfosis según los documentos empleados y las etapas de la vida contadas, pasos de la elegía a la oda, del impresionismo al expresionismo; o sofisticación, hiperreacción ante el servilismo funcional" (Madelénat 1984: 151-152).

En otra dirección, Caballé (2005: 53-54) añade dos nuevas diferencias a las enumeradas por Lejeune entre biografía y autobiografía, ambas de tipo metodológico y surgidas desde una perspectiva de las ciencias sociales: el acopio de material y la pretensión de objetividad del biógrafo frente a la "selección intencional de actuaciones" de la autobiografía; el control absoluto del texto por el autor de esta última frente a la no imposición de restricciones al objeto de estudio - la vida del biografiado- por el biógrafo. Pierre Bourdieu, en cambio, ha ido más lejos y ha puesto en duda en "L'illusion biographique" (1986) la pertinencia del propio género biográfico, discutiendo no sólo el supuesto temático de que una vida pueda ser una historia sino la propia idea de la existencia de un sujeto individual y autónomo, sustraído a su historicidad e interconexión social.

Pero, tipológicamente y con Lejeune, la peculiaridad fundante de la naturaleza del género biográfico se encuentra a mi entender en esa doble conexión de aquella instancia

En la autobiografía la relación es de identidad [=] en ambos casos, y el narrador siempre autodiegético. 
que, más que un personaje protagonista-sobre todo cuanto más nos alejemos de lo narrativo y nos acerquemos a lo ensayístico-, sería mejor denominar sujeto biográfico: de un lado, temático y semántico, el vínculo de similitud del mismo con su modelo personal real [ $\sim$; de otro, enunciativo y actancial, la relación de obligada ajenidad de aquel $[\neq]$ con respecto al autor y el narrador -frente a la autobiografía-, se planteen estos dos últimos como personas idénticas o no. No obstante, ambas cuestiones requieren de una matización.

La primera, recogiendo la distinción de Magné(1989: 163) entre lo vivido y lo biográfico, entre los hechos y dichos que constituyen la vida de un individuo como persona física y lo vivido según es contado por un relato autobiográfico, porque toda textualización referencial implica un proceso de transdiscursivización en el que se dan determinadas operaciones que transforman la realidad externa en otra semiótica y distinta: Ricoeur (cit. en Dosse 2007: 95) llama représentance [ ${ }^{*}$ representancia] a esta similitud representativa, mediada y transfigurada, entre el sujeto biográfico textual y el modelo o persona física extratextual y, en otros términos pero en la misma dirección, Kendall (1965: 147) plantea que la biografía sería "la simulación en palabras de una vida”.

La segunda, porque la ajenidad y distancia, a diferencia de la autobiografía, entre sujeto de la enunciación y del enunciado no supone en absoluto ningún principio de objetividad ni neutralidad absoluta, por mucho que así se pretenda e incluso se instituya en la convención de lectura de un posible pacto narrativo, en este caso biográfico, autor-lector (Dosse 2007: 95). Efectivamente, incluso en los estudios biográficos más rigurosos y pretendidamente científicos, la percepción y relato de la vida de una persona por parte de cualquier autor-investigador está vinculada no sólo a su modelo teórico, enfoque, pretensión y planteamiento sino asimismo a determinadas mediaciones externas que, al menos y siguiendo a J.C. Davis (2005: 35-47), se organizan en cuatro órdenes de cuestiones: documentales, sociales y políticas, de la persona o el yo en la biografía y culturales ${ }^{11}$.

11 La influencia social de la biografía ha sido siempre enorme, puesto que la transformación de algunas vidas individuales en sujetos biográficos de distintos textos históricos, científicos, ensayísticos o literarios (del individuo al modelo referencial que representa luego el sujeto biográfico, y de este último al referente o modelo social) no solo tiene una capacidad ejemplificadora y aleccionadora, didáctica y moral, sino también culturalmente constructiva al erigir las vidas célebres (hazañas, ideas, inventos, lecciones de vida, trayectorias morales, comportamientos épicos o amorosos, etc.) en partes singulares de un determinado modelo ideocultural y del imaginario colectivo general. Sirvan de ejemplo los 284 biopics [biographical pictures] que los grandes estudios de Hollywood crearon entre 1927 y 1960 sobre figuras célebres (Jesucristo, Cleopatra, Napoleón, Lincoln...) y que, según Custen (1992: 3), no solo pasaron casi todas ellas la censura sino que construyeron un relato biohistórico modelado.

Si esto siempre ha sido así, incluso en la etapa encomiástica de las vidas, aún ocurre más con la creación moderna de las biografias en el siglo XVIII (Johnson, Bosswell), su afianzamiento en el siglo XIX con la ayuda de los diccionarios y repertorios profesionales y especializados biográficos y su popularización y gran circulación como ediciones populares en todo el siglo XX. En esta centuria además, su uso metodológico para ciertas ciencias o disciplinas (microhistorias, biografemas, historias de vida) y, sobre todo, su transducción o transmedialización a otros medios de comunicación (películas de cine, series radiofónicas y televisivas) y su paso a la gran semiosfera global que en el siglo XXI constituye internet (wikipedia y repertorios biográficos electrónicos especializados) han aumentado su popularidad e influencia. 
Cabría definir pues, tras ambas breves consideraciones, el antedicho sujeto biográfico como la figura textual central resultante en una biografía de las transformaciones provocadas por las operaciones tanto textuales como extratextuales sobre el modelo de una determinada persona física.

\subsection{LA BIOGRAFÍA, ENTRE LA CIENCIA Y LA LITERATURA}

Desde una perspectiva cronológica ${ }^{12}$, la biografía aparece en el siglo $\mathrm{V}$ antes de Cristo, al mismo tiempo que la Historia pero como un género autónomo y distinto, vinculado al sentido de su origen etimológico, ßíos, a la vez vida y modo de vida, esto es, no solo vida en su planteamiento biológico sino, también y fundamentalmente, social, lo que explica la dimensión de tipo, el carácter de paradigma y modelo social, del personaje en muchas de estas obras. Según Momigliano, ya desde su fundación y en todo el mundo antiguo, la biografía se distingue claramente de la historia y nunca fue considerada como tal (cit. en. Dosse 2007: 123), si bien Valcárcel duda de esta separación aludiendo a los propios testimonios en retóricas y prólogos del mundo antiguo sobre el relato biográfico (Valcárcel 209: 28-29).

Pero el tradicional cultivo historiográfico de los retratos y semblanzas, de la historia prosopográfica, el uso de la biografía -relatos de vida, biografemas, microhistorias, etc.en los recientes estudios sociales, antropológicos o de historia de las mentalidades, etc. permiten establecer vínculos entre biografía e historia. De hecho, J.C. Davis reivindica epistemológicamente la adscripción de aquella a esta: "La descripción no-ficticia de una vida basada en los registros de esa vida (oral, escrita, visual, mnemónica) es esencial e ineludiblemente un ejercicio historiográfico" (2005: 32).

Al otro lado, se encuentran los no pocos defensores del estatuto casi literario, novelesco, de la misma, empezando por el propio Barthes, que ya escribió en 1971 en $\mathrm{Tel}$ Quel que "toda biografía es una novela que no osa decir su nombre" (cit. en Dosse 2007: 307). Y también Ricoeur, a quien biografió el propio Dosse -Paul Ricoeur, les sens d'une

\footnotetext{
12 Con respecto a la evolución histórica de la biografía, Marc Fumaroli (1987: 3) distingue dos épocas fundamentales: la de las vidas, que llega hasta el siglo XVII, y la de las biografias, que surgen con la ruptura moderna. Daniel Madelénat (1984: 34) diferencia tres grandes y sucesivos paradigmas: la biografía clásica, que llega hasta el siglo XVIII, la romántica, que alcanza desde entonces hasta mediados del XIX y aporta una nueva necesidad de intimidad y conocimiento de la vida familiar, y la moderna, más radicada en la historia y más enriquecida por las lecturas, la sociología y el psicoanálisis. François Dosse (2007: 123, 195 y 229) en cambio, plantea la existencia de tres grandes modelos constructivos sociohistóricamente determinados: la biografía de la edad heroica, desde la antigüedad hasta la época moderna, tiene como función social la identificación en su pretensión de proponer ejemplos y moralidades para generaciones futuras; la biografía modal, propone alcanzar el tipo ideal a través de un relato de vida particular y representativo, lo singular entra en lo general y el individuo tiene valor como ejemplo de un colectivo; finalmente, la biografía de la edad hermenéutica, la más contemporánea, se centra en la reflexividad y acepta la subjetivación, bien en tanto que aproximación al otro como alguien a la par diferente y a la par alter ego, bien considerándolo como un ser diverso atravesado por multitud de adscripciones y códigos conformadores de su identidad plural.
} 
vie-, señalaba en Soi-même comme un autre esta tensión entre el modelo real, imposible de reproducir, y la presencia de la ficción, inevitable para el biógrafo: la biografía sería así "una mezcla inestable entre fabulación y experiencia viva" (Ricoeur 1990: 191).

Dosse (2007: 13 y 55) plantea en cambio el carácter híbrido del género biográfico y su dificultad de clasificación en una disciplina, sometido a las permanentes atracciones de los polos de lo histórico y lo ficticio: "género híbrido, la biografía se sitúa en la tensión constante entre la voluntad de reproducir según las reglas de la mimesis el pasado real vivido, por un lado, y por otro, el polo imaginativo del biógrafo que debe recrear, según su intuición y sus capacidades creativas, un universo perdido" (Dosse 2007: 55). Y Hamilton ${ }^{13}$ incide asimismo en el aspecto creativo e interpretativo de la biografía al definirla en su historia de la misma como "una producción creativa y no ficcional dedicada a dejar constancia e interpretar vidas reales" (Hamilton 2007: 1).

Igualmente, en cierto modo replanteando esa misma atracción dual de la ciencia/ historia y la ficción/literatura, frecuentemente se ha aludido a la existencia de una doble modalidad del género biográfico: la tendencia hacia el ensayo científico o interpretativo y la orientación hacia la narrativa (Madelénat 1984: 145), fundamentalmente por la presión literaria de la novela de una parte y de ciencias ${ }^{14}$ como la antropología, biología, sociología, psicología científica o psicoanálisis de otra (Caballé 2009: 24), pero asimismo por la acentuación o minoración de aspectos ficcionales y creativos. Por ejemplo, Frank (1980: 505-507) destaca la existencia de dos grandes modalidades biográficas: la analitica, que es de tipo ensayístico, interpretativa y no necesariamente factualista, y la narrativa, que emplea discursivamente estrategias narrativas para tematizar menos rigurosamente la historia de la vida de una persona destacada o conocida.

13 El mismo crítico ha resumido en otro trabajo las diferencias objetuales y de método existentes entre la investigación biográfica y la del novelista y la del historiador (Hamilton 2008: 64).

14 También en el campo de los estudios literarios se ha utilizado la biografía como base. Así ocurre en el caso de toda la numerosa serie de trabajos positivistas [Vida y obra de...] centrados en la relación vida/obra del autor, un vínculo tan estrecho y fructífero, tan permanente y utilizado que, en determinados casos, ha terminado por contaminar o confundir ambos términos de la relación, hasta tal punto que "la narración de la vida se presenta como explicación de la obra", lo que ha hecho a Antoine Compagnon acuñar el término sincopado de vieuvre ["vidobra] para explicar esta fusión (cit. en Dosse, 2007: 80). La biografía ha sido asimismo la base de la llamada crítica biográfica, cuyo máximo exponente fue Charles Sainte-Beuve, a mediados del siglo XIX, que basaba su método en buscar las explicaciones de las obras literarias en los aspectos biográficos y caracterológicos de sus autores, entre los cuales cabe inducir una tipología psicológica que denominaba familias del espiritu y cuya relación con sus creaciones literarias era productivamente tan estrecha que cabía representarlas con el refrán "de tal palo, tal astilla" (cit. en Wellek, 1972: 63). Por último y en cambio, la psicobiografía concibe tal relación desde un modelo teórico distinto, el psicoanálisis, que establece como objeto epistemológico el sujeto y que, desde distintos planteamientos teóricos (Freud, Jung, Lacan, etc.) y en diferentes líneas críticas, bien estudia directamente al hombre para encontrar sus huellas en el texto (psicobiografía), bien examina primeramente este para advertir los mecanismos del inconsciente del creador (psicocrítica de Mauron) o sus efectos en el lector (psicolectura). La tendencia psicobiográfica fue inaugurada por Freud en sus trabajos Un recuerdo infantil de Leonardo da Vinci (1910) y Dostoievski y el parricidio (1928). 
Cabría considerar pues que la biografía, marcada por su dimensión no ficcional en su esencia y el sujeto biográfico en su tema, se sitúa en el centro de una estructura de doble imanación polar en la que, según tienda más en cada uno de esos dos aspectos, ontológico y temático, bien hacia la referencialidad -con pretensión de veracidad, más objetivista o más interpretativa- o hacia la ficcionalidad - con una verosimilitud y coherencia semántica que puede tender a lo realista o incluso lo fantástico-, bien hacia el sujeto biográfico como objeto científico o como personaje narrativo, se aproxima respectivamente más bien al ensayo histórico o científico bien a la narrativa literaria (novela biográfica). Véase esta situación en el siguiente esquema:

Cuadro 1

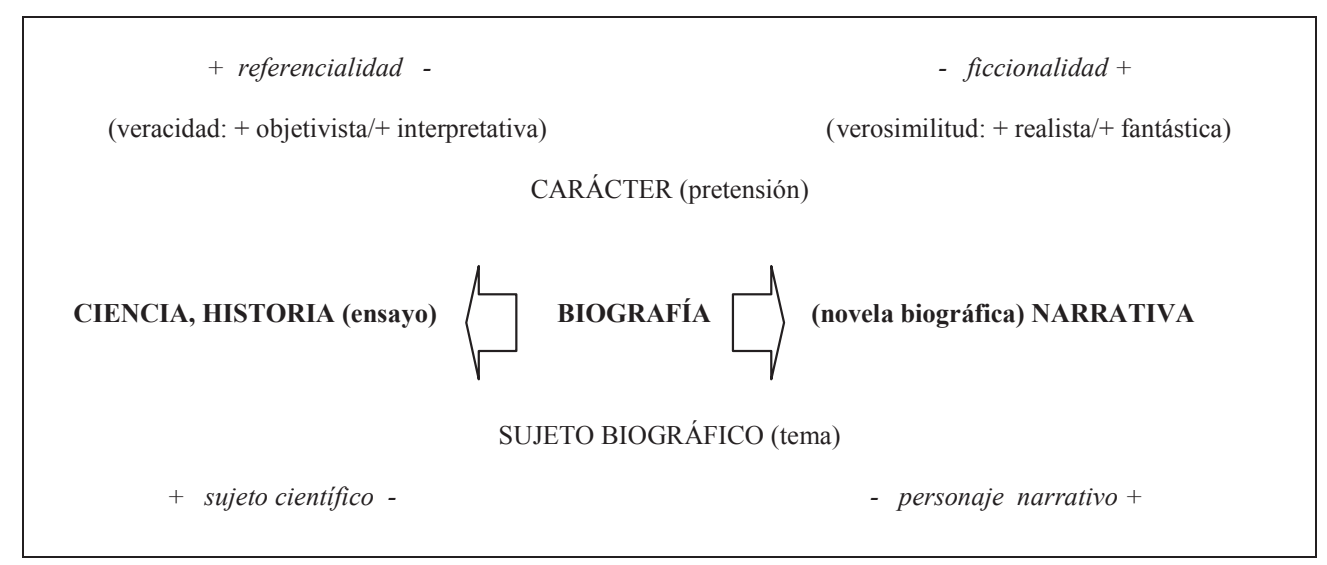

\subsection{LA NOVELA BIOGRÁfica}

En el ámbito literario, del mismo modo que la autobiografía mantiene una especial vinculación con otros géneros situados en la órbita enunciativa y temática del yo mismo y el mí mismo como las memorias, la confesión, el diario o el autorretrato, la biografía la establece con las modalidades más sintéticas y descriptivas del retrato (Españoles de tres mundos de Juan Ramón Jiménez) y la semblanza (Generaciones y semblanzas de Pérez de Guzmán), y, muy especialmente, en su tendencia hacia la narrativa ficcional ${ }^{15} \mathrm{y}$ como ya he

15 Conviene mencionar asimismo la posible existencia de dos fórmulas conectadas con el género biográfico, raras — pero no inexistentes - e inversas entre sí: la primera porque falsea la naturaleza de la biografía al proponerse como tal sin serlo; la segunda porque, siendo de tema biográfico, oculta su carácter. Se trata, de un lado, de la que cabe denominar biografía ficticia o apócrifa, un ensayo verosímil pero falso sobre un sujeto biográfico inexistente, sin correspondencia con ningún modelo físico real: el ejemplo más conocido en la tradición hispánica es la obra de Max Aub Jusep Torres Campalans (1958). Cabe hablar, de otro lado, de biografía 
planteado, con la novela y determinados subgéneros novelescos: es evidente la cercanía con, según los casos concretos, la novela-río, la novela de aprendizaje o bildungsroman y la novela histórica (caso de esta obra de Vázquez Montalbán); no obstante, evidentemente, la máxima proximidad se produce entre biografía y novela biográfica.

He caracterizado diseminadamente la biografía como un relato no ficcional, ajeno y retrospectivo, usualmente en tercera persona, en prosa y en orden cronológico, que tematiza la trayectoria vital de una determinada personalidad con propósito esclarecedor, divulgativo o ejemplificador. Desde esta perspectiva, aparecerían como elementos configuradores permanentes de la biografía: en la dimensión ontológica, su naturaleza no ficcional, primordialmente referencial; en la relación del sujeto de la enunciación y del enunciado, su obligada desidentificación y alteridad $[\nexists]$ entre autor, narrador y personaje; en la perspectiva del tiempo del relato respecto a lo contado, su retrospección; en el tema, no solo su planteamiento nodal de que la referencia extratextual es la vida de una persona conocida sino el establecimiento de una relación de similitud representativa [ -$]$-de représentance con el citado término de Paul Ricoeur-, entre el sujeto biográfico textual y la persona física extratextual; finalmente y en el propósito, su orientación hacia la veracidad y su pretensión científica o de estudio, pedagógica o moral. Serían rasgos tipológicos muy frecuentes, pero no constantes, la presencia de un narrador heterodiegético en tercera persona, la linealidad temporal y el orden cronológico general del relato y el empleo de la prosa.

Aparte de estas tres mismas características últimas usuales (heterodiégesis, prosa y orden cronológico y lineal), la novela biográfica ${ }^{16}$ comparte con la anterior su carácter narrativo, aunque no ensayístico ni tendente hacia la referencialidad, su alteridad de autor, narrador y personaje y, sobre todo y constitutivamente, su centramiento temático en un sujeto biográfico. Sin embargo, como puede apreciarse en el lado derecho del cuadro 1, este tipo de subgénero narrativo -y no ensayo científico o interpretativo-, definido esencialmente

o, mejor, novela biográfica oculta o simulada cuando, por cualquier motivo, bien se camufla bien se esconde la naturaleza del género mediante menciones paratextuales — normalmente título o subtítulo — falsas o equívocas: es este justamente el caso de Autobiografía del general Franco, que se denomina autobiografía sin serlo en la cubierta, y se postula como biografía en la historia narrativa sin serlo exactamente tampoco, pues precisamente se trata de una novela biográfica.

Obsérvese la similitud de estas dos fórmulas, biografía ficticia y novela biográfica, con las dos grandes líneas correspondientes de la modalidad autobiográfica, autobiografía ficticia y novela autobiográfica, señaladas y estudiadas por Alberca (2007: 93-99 y 99-113).

16 Se ha aludido también repetidamente a la biografía novelada, que en cierto modo se situaría en el espacio entre la biografía y la novela biográfica, si bien habría que adscribir architextualmente de modo preferente a la primera, porque, pese a su mayor libertad y elaboración estilística -o al contrario con una escritura menos elaborada y una intención más divulgadora y popular-, mantendría su dimensión referencial, carácter ensayístico, pretensión de veracidad y aspiración de fidelidad del sujeto biográfico al modelo real biografiado.

A título meramente ilustrativo, pueden citarse algunos ejemplos de novelas biográficas muy recientes como La pasión de Michel Foucault de James Miller, Relámpagos de Jean Echenoz, sobre el inventor Nikola Tesla, o Como caminos en la niebla de José Morella, sobre el psiquiatra anarquista Otto Gross. Más antigua y conocida es Soldados de Salamina de Javier Cercas, sobre el fundador de Falange Rafael Sánchez Mazas. 
como tantos otros en clave temática y caracterizado globalmente por los elementos generales propios de la novela, se alinea ontológicamente en el ámbito de la ficcionalidad, que se vincula a la verosimilitud -y no a la pretensión de veracidad- sea en una dimensión más o menos realista, y otorga más libertad y menos mimetismo a la representación del modelo físico real como sujeto biográfico, que tiende ya a convertirse en un personaje -alejándose de constituir sólo un objeto científico- en el relato literario.

\section{Autobiografía del general Franco como novela biográfica dialógica, política y CRÍTICA}

Una solicitud editorial, en el Introito, y el manuscrito Autobiografia del general Franco como respuesta de Pombo, en el Epílogo, son la excusa para un ajuste de cuentas narrativo del antifranquismo con el franquismo, de la memoria con la historia, de Vázquez Montalbán con la represión. Pero el carácter crítico, político y dialógico del relato históricobiográfico interior y trascendente [del franquismo y Franco] se instala ya en los mismos márgenes actanciales (destinador/destinatario: encargo/entrega del libro) de la acción narrativa, que en principio podrían haber sido más asépticos pero que tampoco quieren escapar a esa implicación crítica y política absoluta de toda la obra:

Y yo te digo, tú, tú, metido en la piel de Franco has de contar su vida a las generaciones de mañana. Es decir, te propongo que escribas una supuesta autobiografía de Franco que será el número uno de una colección titulada: A los hombres del año dos mil. Retuve una respuesta inmediata, calculándola, buscando una frase que expresara mi amargura, pero también mi agradecimiento. Sobreestimas mi capacidad de distanciamiento, se me ocurrió al fin y él arqueó una ceja, una sola ceja. ¿Por qué has de distanciarte? ¿No eres un técnico en divulgación? Tú métete en la piel de Franco y excúlpate ante la historia. Todo lo demás es cosa tuya. Pero es que... pero es que... Me atreví a decirle que desde niño Franco ha sido una sombra que ha modificado mi vida, la de mi familia, y que algo de sarcasmo tiene que yo sea ahora su autobiógrafo, algo así como un biógrafo secreto, de cámara. No, no, estás muy equivocado. El libro lo firmarás tú, no lo firmará Franco ${ }^{17}[\ldots]$. Crecí a la sombra de su miedo, forcejeé contra Franco con tanta vergüenza como miedo y finalmente me di cuenta de que a Franco sólo le había vencido la biología y ni siquiera el olvido de su rastro era mi victoria, sino que se me convocaba para sacarle del olvido y convertirlo en memoria para los tiempos venideros.

\footnotetext{
17 Se trata de un juego de triple inversión en la relación autor/obra: el editor encarga una biografía; Pombo realiza una falsa autobiografía política y crítica; Vázquez Montalbán escribe una novela [biográfica], a la que titula "autobiografía" en ese juego especular de desplazamientos de responsabilidad autoral y, a la par, de identificación —indirecta— con el personaje-escritor Pombo.
} 
$[\ldots]$

-Me quedo la obra. Respeto nuestro acuerdo económico. Pero creo que solo voy a hacer uso del monólogo del general, es decir, voy a quitar todos los ruidos.

[...] Me sentía demasiado cansado para ser digno. La carpeta se deshinchaba en el centro de la mesa, como si de ella escaparan todas las ánimas del antifranquismo para dejar al general consigo mismo, un Franco par lui même a la manera de la literatura divulgadora francesa de los años cincuenta.

[...] Mientras volvía a casa pensaba que tal vez sin las notas críticas sin duda, usted mismo, ya que por la boca muere el pez, se bastaba y se sobraba para autocondenarse al infierno de la memoria del futuro. Al fin y al cabo yo no era responsable exclusivo del juicio de la historia, yo no era la conciencia del mundo. ¿Por qué debía asumir la empresa de resucitar a sus víctimas, general? (Vázquez Montalbán 1992: 20 y 652).

Pero no estamos ante un ensayo biográfico o autobiográfico sino ante una obra que presenta la configuración architextual y rasgos de la novela y que está construida con las libertades literarias de la misma, comenzando primero con la posibilidad de oponer al franquismo un contradiscurso alternativo y democrático que activa la crítica de los actos y palabras de Franco permanentemente, que filtra y selecciona sus palabras, ideas, reflexiones y sentimientos mediante el censor tamiz del narrador (yo)/personaje (Pombo), que hace convivir como seres de papel a personajes procedentes del mundo ficcional y del universo físico real y que elabora técnica, lingüística y estilísticamente el relato con esmero y mimo, en suma, que prima la singularidad literaria sobre la ensayística y científica. Asimismo y después, el sujeto biográfico Franco, sin abandonar nunca el centro temático, se desliza, como personaje, hacia la condición de actor en un relato secundario o enmarcado de la diégesis primaria y, como enunciante, hacia la pronunciación de un discurso continuamente discutido, contradicho y probatoriamente desmontado. Y por todo lo anterior, aun manteniendo una dimensión mucho más realista que fantástica y más documentada que inventada, la obra se escora tremendamente por último hacia el espacio de la ficcionalidad y la verosimilitud, de la memoria y la subjetividad, antes que hacia la Historia y la verdad, el olvido y el relato oficial. De estas tres formas se posibilita la construcción de una narración biográfica crítica, se permite contravenir dialógica y discursivamente la historiografía oficial sobre Franco y el ideario y práctica política franquista, se crea una novela más política que biográfica y más justiciera que neutral: Autobiografía del general Franco es una novela biográfica sobre el citado dictador y la dictadura cuyas características definitorias son la dimensión política, el tono crítico y la construcción dialógica.

La dimensión política abarca el texto completo: preferentemente el franquismo y la figura personal, militar y política de Franco, pero también su continuidad y la transición democrática, las ideas y el Partido Comunista, sus replanteamientos, la extrema izquierda y la Falange, el marxismo y el idealismo burgués, las figuras señeras de la política comunista mundial y espańola... Ya desde el principio se enuncia la intención de la obra: "Resucitarle para matarle. ¿ No estoy en condiciones de cumplir el sueño de media Espańa vencida?”; 
asimismo su planteamiento objetivista y confrontador pero no manipulador del discurso y la imagen de Franco: "No. No puedes dar pie a que se diga que Franco es tu víctima, no puedes convertirlo en mártir de tu escritura" (Vázquez Montalbán 1992: 22). Sin embargo, el carácter político del relato no solo deriva de esa impregnación temática sino de la contraposición dialógica y, sobre todo, la transdiscursivización de los sociolectos -en el sentido de Cros (1998) y Zima (1980; 1982)-, esto es, la incorporación y recodificación de los discursos de distintos grupos sociales al texto narrativo: así, frente al discurso históricopolítico y personal de Franco, enunciado directamente desde su -supuesta- propia figura y voz, se alzan los distintos lenguajes sociopolíticos alternativos de los grupos antifranquistas de la España de la dictadura, particularmente de su tramo final y de la transición democrática, depositados en el relato o comentarios de Marcial Pombo y sustentados asimismo con la intertextualización de numerosas fuentes documentales (testigos, textos históricos, políticos o periodísticos, etc.). Enormemente representativo del aspecto político de la obra es el diálogo casi final entre el editor y Pombo:

-¿De qué ruidos me estás hablando?

-Al empezar te mantienes prudentemente en tu papel, pero poco a poco vas interrumpiendo más al general, le vas contradiciendo, vas aportando elementos subjetivos, que a ti te parecen objetivos, que anulan el mensaje del generalísimo. Estos ruidos pertenecen a una visión crítica de la historia [los subrayados son míos] que cada vez tendrá menos sentido, que pertenece a la memoria de los que vivieron con Franco, ni siquiera es estrictamente tu memoria. Pero es que, no contento con impedir el discurso coherente, es decir, el mensaje del general, además le cuentas tu vida, integras tu vida en la suya o la de tus padres o la de tu mujer, tus hijos, tus amantes. Es inaudito. ¿Qué coño pintan estos ruidos en este canal, en este mensaje? ¿Qué coño le importaría a la generación del futuro que tú trataste de aguarle la fiesta a Franco tirando octavillas contra Eisenhower o que Serrano Suñer con le caía bien a dońa Carmen o lo que sea?

-Pero me estás diciendo que Franco es el único dueño de su imagen. De que yo no tengo derecho a desenmascararle.

-Eso es cosa de historiadores.

-Los historiadores del futuro, incluso los del presente, no habrán tenido la vivencia de la crueldad, la desfachatez, la mediocridad del franquismo.

[...]

-El franquismo fue un ruido, eso sí que fue un ruido que interrumpió el mensaje de la democracia... de la libertad...

-Corta el rollo, Marcial. No me hagas el mitin.

Se recostó contra el respaldo y me observó como se contempla a una especie zoológica en la que hasta entonces no se había reparado.

-Mi padre y tú habéis sido demasiado... históricos, pero dando al adjetivo un sentido moral. La historia sólo puede tener un sentido fáctico, lo que está hecho, 
hecho está y sólo interesa resaltar lo curioso de su causalidad, no la moral de su causalidad. ¿Cómo puedes sancionar una causalidad de algo que ya se ha producido? En definitiva, Franco es el que hizo la historia y vosotros la sufristeis. Mala suerte. Eso es todo. Dentro de cien años vuestras sensaciones de odio, impotencia, fracaso, miedo no estarán en parte alguna y Franco al menos será siempre, para siempre una voz de diccionario enciclopédico, unas líneas en los manuales o en los vídeos o en los disquets [sic], en cualquier soporte de memoria seleccionada para el futuro. Y en esas pocas líneas no cabrá vuestro sufrimiento, vuestra rabia, vuestro resentimiento (Vázquez Montalbán 1992: 651-652).

La novela es, evidentemente también, un relato biográfico expresa y profundamente crítico, que enlaza con la rotura de la biografía encomiástica que abrieron a principios del siglo XX Edmund Gosse con Padre e hijo (1907) y Sigmund Freud con Un recuerdo infantil de Leonardo da Vinci (1910); ambas presentan críticamente a sus modelos reales, como un padre represor y puritano y un artista renacentista homosexual respectivamente (Hamilton 2008: 18). Pero la condición esencial de la obra de crítica directa y ácida, dura y profunda, de Franco y el franquismo no esconde que esta, unida al suave sentido del humor y sobre todo la distanciadora y permanente ironía que se halla en toda la producción narrativa de Vázquez Montalbán, aflore con enorme frecuencia. La ironía, que es sobre todo inicial porque el relato se va endureciendo y politizando conforme avanza el discurso franquista, alcanza, respectivamente y por ejemplo, al marxismo, la crítica literaria o la vida del propio escritor comunista Pombo:

[...] utilizaba frecuentemente a Sartre como punto de referencia, extremo considerado no muy ortodoxo en aquellos años en que tras las posiciones de Sartre ante lo ocurrido en Budapest y Poznan no se sabía muy bien si era un pequeño burgués existencialista o un nexo imprescindible entre el idealismo burgués más avanzado y el pensamiento materialista dialéctico".

$[\ldots]$

Conte decía que yo "había perseguido la literatura durante toda una vida" y aunque no se comprometía a asegurar que la había alcanzado, sí explicaba muy bien mi novela durante tres cuartas partes de su trabajo [...] y la cuarta parte restante la dedicaba a darme consejos sobre cómo escribir la próxima”.

$[\ldots]$

que terminó con mi separación, la marcha de Lucy y los nińos, alegando no crueldad mental sino insuficiencia de espíritu, causa que ningún juez le habría admitido, pero que yo le admití porque no se puede convivir con alguien que te cree invisible" (Vázquez Montalbán 1992: 10, 16 y 12).

La crítica, que se suaviza y coapta con la ironía y el humor en el resto de figuras no políticas, muchas de ellas correspondientes también a personas físicas, es frontal y 
demoledora en el caso de Franco y el franquismo, siempre, desde el principio hasta el final, socavando todo, incluso la niñez y la muerte del dictador. Así, por ejemplo, en el primer capítulo sobre la infancia del general, Pombo va introduciendo diferentes intertextos que contradicen las versiones políticas oficiales del franquismo respecto a la niñez y familia de Franco: dos trabajos históricos de Hill y Ramón Garriga contravienen la idoneidad de la educación del general; tres testimonios familiares (de la hermana, la sobrina socialista y el primo militar del general) discuten la reforma de la vivienda familiar por la mujer de Franco, la idealización del ambiente de El Ferrol a finales del siglo XIX y el carácter del padre; parte del guion de la película Raza, escrito por Franco bajo el seudónimo de Jaime de Andrade, es utilizado para desmontar la falsificación encomiástica de la figura del padre del general y el deseo oculto de matar al padre (Vázquez Montalbán 1992 : 24 y ss.) Y también, en uno de los últimos fragmentos de la novela, Pombo se dirige directamente al ya fallecido general para criticarlo dura y directamente:

Los demás [nietos y parientes] tienen posibles y se han vendido o esperan vender fincas hoy abandonadas que usted tanto cuidó u otros bienes que siguen siendo secreto de Estado. Porque el Estado, lo oficial, se ha portado bastante bien con ustedes y con usted. Apenas si ha habido revisiones críticas, nadie ha querido tirarse la memoria por la cabeza y aquella idea parida por el sociólogo Linz, hijo de madre dirigente de la Sección Femenina, de que usted no había sido "totalitario" sino "autoritario" ha causado estragos y ha lavado la cara de todos los que se la ensuciaron, impasible el ademán, más o menos firmes, cara al sol del amanecer y a la luna de tanto fusilamiento y tortura. Usted fue declarado material humano para la sanción de la historia y hoy tienen la sartén por el mango una raza de historiadores objetivos que reparten culpas repartibles y olvidan la culpa inicial de que usted empezó el tiroteo en medio de tanto alboroto y que conservó el tiroteo hasta el final de sus días, totalitario o autoritario, a usted le daba lo mismo, no hay mal que por bien no venga y hoy yunque, pero mañana, sin prisas pero sin pausas... martillo. Sin prisas pero sin pausas le estamos olvidando general, y olvidar el franquismo significa olvidar el antifranquismo, el esfuerzo cultural ético más generoso, melancólico y heroico en el que se resistieron puñados de mujeres y hombres [...] (Vázquez Montalbán 1992: 662).

El dialogismo en sentido bajtiniano (1986) no sólo recorre sino que funda y estructura la obra: son dos y siempre opuestos, más que contrapuestos y yuxtapuestos -que también-, los personajes, los enunciadores, las imágenes de Franco, los discursos personales, históricos y políticos. Desde el principio hasta el final, desde lo individual a lo colectivo, desde lo privado a lo político, cada intervención de Franco comporta la contradicción discursiva de Pombo, bien directa bien documentada. Esta es la primera vez que contrarreplica el escritor al militar a propósito de su apellido: "Menos haches, general. Su apellido materno real siempre se escribió Baamonde, hasta que usted, ya en la etapa de su despegue epopéyico, 
le añadió la hache intercalada para subirlo de estatura social". Y esta, ya al final del libro, la única que se calla por la innecesariedad de comentario ante las delirantes últimas palabras de Franco, que, tras un "Arriba España, Viva España", cierran su monólogo en cursiva: "Y cuando llegue la muerte la miraré a los ojos, conocedor de su irreversible ceguera. No espero disuadirla de su propósito, al contrario, sino entregarle mi mirada privilegiada y dejarla para siempre en posición descanso". Nada escapa entre principio y fin al discurso alternativo: incluso el estilo del habla del general es criticado por Pombo, que califica su prosa de "redaccional, retórica y bachilleril" (Vázquez Montalbán 1992: 23, 646 y 408).

Pero, más que en las propias voces y opiniones de Franco y Pombo, la contraposición dialógica se sostiene y se transforma en discurso, plural y social de un lado, verosímil y convincente de otro, mediante la intertextualización de diferentes citas o extensos pasajes, acaso no tanto en los textos atribuidos a Franco como en los supuestamente escritos por Pombo. Franco menciona algún medio de comunicación (Radio Nacional, Ya, La Estafeta literaria...), el catecismo, alguna frase de algún escritor (Manuel Machado, Pemán, Giménez Caballero), comunicados militares y ciertos comentarios políticos famosos, propios o ajenos (José Antonio), pero con una escasez comparada que implícitamente quiere evidenciar la pobreza intelectual y la minoría cuantitativa y cualitativa de las opiniones legitimizadoras del régimen y su caudillo. Pombo, en cambio, utiliza, de principio a fin, un material intertextual cualitativa y cuantitativamente amplio, un complejo y variado aparato crítico $^{18}$ : textos históricos (Hill, Ramón Garriga, Sánchez Soler, Ángel Viñas, Brenan, Carlos Fernández, Josep Fontana), científicos y filosóficos (Ortega y Gasset, Maritain, Castilla del Pino, Hume, Luciano Rincón), periodísticos ( $A B C$, Informaciones, El adelantado de Segovia, Liverpool Daily Post, United Press, Ya, Radio Nacional, No importa, Le Figaro, Sunday Pictures, Le canard enchaîné), artísticos y literarios (Jaime Salom, Raza, Clarín, Sender, Fernández Flórez, Maeztu, Hemingway, Bernanos, Marañón, Francisco Mateu, Mauriac, La estafeta literaria, Lorca, lírica popular bélica, Umbral, El Guernika, Claudel, La del manojo de rosas), documentales de carácter político o religioso (NO-DO, Diario de una bandera, Franco, Azaña, Gil Robles, Andreu Nin, Indalecio Prieto, March, Keipo, Kindelán, Unamuno/ Millán Astray, José Antonio, Signo, Obispo Olaechea, Padres Ripalda y Astete, Vicario Gonzalo, Eliseo Bayo, A Nosa Terra, Areílza, Culbertson, octavillas políticas, Navarro Rubio, Carrero, López Rodó, Cabanillas, Vicente Mortes) y sobre todo testimoniales directos (Pilar Franco, Pilar Jaráiz, Carmen Díaz, Salgado Araújo, Vicente Guarner, Sofía Subirán, Luis de Galinsoga, Hidalgo de Cisneros, Fermín Galán, Calvo Sotelo, Ramón Franco, Sáinz Rodríguez, Guillermo Cabanellas, Roda de Campins, Ansaldo, Ruiz Vilaplana, Serrano Súner, Gloria Ridruejo, José Antonio Silva y Carmen Díaz, Giménez Arnau, Vegas Latapie, Bernabeu, Carmen Polo, San Martín).

\footnotetext{
18 Aparte de dejar constancia de la riqueza referencial e histórica de la novela, de la también compleja urdimbre intertextual de la obra da fe el Índice Onomástico final (Vázquez Montalbán 1992: 665-679), que ocupa 15 páginas a doble columna.
} 
Así pues y como breve conclusión, Autobiografía del general Franco (1992), de Vázquez Montalbán, más que una obra que pueda adscribirse primordialmente de modo architextual a la narrativa histórica o de dictador -con las que guarda evidentes relaciones-, constituye un excelente ejemplo de novela biográfica, si bien en la línea desmitificadora y crítica que ya abrieron a principios del siglo XX los trabajos citados de Gosse sobre su padre y de Freud sobre Leonardo. Empleando la arquitectura dialógica a que aludió Bajtín, transdiscursivizando los sociolectos o lenguajes de los distintos grupos políticos y sociales planteados por la sociocrítica e intertextualizando numerosas pruebas documentales (testimonios, confesiones, textos históricos, periodísticos, políticos, artísticos, etc.), el escritor barcelonés produce una magistral novela sobre el dictador español -oponiendo el discurso antifranquista, desmitificador y democrático, a la historiografía oficial del régimen-, cuyas características esenciales son la urdimbre antitética de estructuras e ideas, el núcleo temático político a la vez que biográfico y la revisión crítica de la historia española de la mitad del pasado siglo XX.

\section{Obras Citadas}

Alberca, Manuel. 2007. El pacto ambiguo. De la novela autobiográfica a la autoficción. Madrid: Biblioteca Nueva.

Alonso, Amado. 1984. Ensayo sobre la novela histórica. Madrid: Gredos.

Bajtín, Mijaíl. 1986. Problemas de la poética de Dostoievski. 1929. México D.F.: Fondo de Cultura Económica.

Bal, Mieke. 1987. Teoría de la narrativa (una introducción a la narratología). 1977. Madrid: Cátedra.

Bourdieu, Pierre. 1986. "L'illusion biographique". Actes de la recherche en sciences sociales 62 (1): 69-72.

Caballé, Anna. 2005. "Biografía y autobiografía: convergencias y divergencias entre ambos géneros”. El otro, el mismo. Biografía y autobiografía en Europa (siglos XVII-XX). Davis, Colin J. e Isabel Burdiel (eds.). Valencia: Universitat de València. 49-61.

Cros, Edmond. 1998. Genèse socio-idéologique des formes. Montpellier: Édition du CERS.

Custen, George F. 1992. Bio/Pics: How Hollywood Constructed Public History. Piscataway: Rutgers U.P.

Davis, J.C. 2005. "Decadencia final de una necesidad cultural: la biografía y su credibilidad intelectual”. El otro, el mismo. Biografía y autobiografía en Europa (siglos XVII-XX). Davis, Colin J. e Isabel Burdiel (eds.). Valencia: Universitat de València. 31-47.

Dosse, François. 2007. La apuesta biográfica. Escribir una vida. 2005. Valencia: Universitat de València.

Frank, K. 1980. "Writing Lives: Theory and Practice in Literary Biography”. Genre XIII: 499-516.

Fumaroli, Marc. 1987. "Des 'Vies' à la biographie: le crépuscule du Parnasse”. Diogène 
139: 3-30.

Genette, Gérard. 1972. Figures, III. Paris: Seuil.

Gusdorf, Georges. 1991. "Condiciones y límites de la autobiografía”. Suplementos Anthropos 29: 9-17.

Hamilton, Nigel. 2007. Biography: A Brief History. Cambridge (MA): Harvard University Press. . 2008. How to Do Biography: A Primer. Cambridge (MA): Harvard University Press.

Haro Tecglen, Eduardo. 1992. "Un monumento antifranquista [Autobiografía del general Franco]". Babelia, El País, 31-10-1992. Recuperado de http://www.vespito.net/ $\mathrm{mvm} /$ autob1.html [doi].

Hawthorn, Jeremy. 1997. Studying the Novel. An Introduction. 1985. London-New York: Arnold-Oxford University Press.

Kendall, Paul M. 1965. The Art of Biography. New York: Norton \& Co.

Lejeune, Philippe. 1975. Le pacte autobiographique. Paris: Seuil. 1980. Je est un autre. Paris: Seuil.

Lukacs, Gyorgy. 1966. La novela histórica. 1937. México D.F.: Ediciones Era.

Madelénat, Daniel. 1984. La biographie. Paris: PUF.

Magné, Bernard. 1989. "La textualisation du biographique dans $W$ ou le souvenir d'enfance de Georges Perec". Autobiographie et biographie. Colloque de Heidelberg. Calle-Gruber, Mireille y Arnold Rothe (eds.). Paris: Nizet. 163-184.

Pimentel, Luz A. 2005. El relato en perspectiva. Estudio de teoría narrativa. 1998. México D.F.: Siglo XXI-UNAM.

Ricoeur, Paul. 1990. Soi-même comme un autre. Paris: Seuil.

Romera Castillo, José. 1996. "Literatura y vida". Las historias de vida y la investigación biográfica. Fundamentos y metodología. López-Barajas Zayas, Emilio (coord.). Madrid: UNED. 77-93.

Sábato, Ernesto y Augusto Roa Bastos. 1998. “Sábato y Roa Bastos, contra viento y marea”. El País 19-7-1998: 26-27. Recuperado de https:/elpais.com/diario/1998/07/19/ cultura/900799201_850215.html [doi].

Valcárcel Martínez, Vitalino (ed.). 2009. Las biografías griega y latina como género literario. Vitoria: Universidad del País Vasco.

Valles Calatrava, José R. (1999). "Relaciones transtextuales entre los discursos político y novelesco". La palabra del poder y el poder de la palabra. Medina, Rubén D. y José R. Valles (dirs.). México-Almería: UNAM-UAL. 209-226. . 2008. Teoría de la narrativa. Una perspectiva sistemática. Madrid-Frankfurt: Iberoamericana-Vervuert.

Vázquez Montalbán, Manuel. 1992. Autobiografía del general Franco. Barcelona: Planeta.

Wellek, René. 1972. Historia de la crítica moderna (1750-1950), III, Los años de transición. 1965. Madrid: Gredos.

Zima, Pierre V. 1980. L'ambivalence romanesque. Proust, Kafka, Musil. Paris: Le Sycomore. 1982. L'indifférence romanesque. Sartre, Moravia, Camus. Paris: Le Sycomore. 
